\title{
Plywood Toys
}

\section{MO ZELL}

University of Wisconsin-Milwaukee

\section{FRAMEWORK}

In 1967 Yale dean Charles Moore in collaboration with Kent Bloomer established one of the first permanent design/build studios in the country, the Yale First-year Building Project. Yale required ALL first-year graduate students to participate in the design and construction of a structure. "Moore saw that getting out of the studio and building something (making) would have several benefits for the students. As a believer in simple tectonics and basic technologies, he hoped students would be inspired by the mechanics of building." (Vlock Building Project summary).

The importance of engaging ALL students in the making process cannot be overemphasized. In its theoretical form, an idea can only be challenged conceptually. Once an idea is given physicality, however, these artifacts (the drawings, models, etc.) can now be used to challenge the idea not only conceptually, but also physically. 1:1 exercises reinforce the notion that how we make things and how we think about them are intrinsically linked.

\section{ARCHITECTURAL TOY}

While traditionally design/build exercises have been implemented at the scale of a space or a building, this exercise, at the scale of an object (and executed by an entire class of junior level students), delves deep into issues of intimate user interaction and tectonics. Students developed a project from conception to fabrication and finished with a better understand of the relationship between ideas and making. The students were asked to design, in teams of two, a transformable toy for a child while using a limited vocabulary of shapes and a single material palette of 5/8" Baltic birch plywood. The deliverables were not models, but the actual toy.

A local museum provided funds for the Baltic ply, allowing students to experiment without the concern of costs. In addition, the museum also displayed the best toy designs alongside an exhibition called Serious Play that highlighted the work of Ann Tyng. This provided students a venue to disseminate their ideas to the public. Children from the local daycare served as toy testers providing dynamic feedback to the student designers. The partnerships along with the design and construction process allowed students to consider spatial and material experiences through tectonics in combination with how users interact with objects in their environment; and how designs benefit from careful consideration and inclusion of specific human experiences. The scale of the toy
MARC A. ROEHRLE

University of Wisconsin-Milwaukee

allowed for this assignment to be completed within a controlled timeframe and served as a primer for a satellite center for the local art museum.

This exercise also reinforced a critical discussion regarding means of fabrication. The laser cutter and CNC mill have been indiscriminately introduced into our design studios. The project offered a way to critically evaluate the roles of these tools relative to design. Students began to recognize that different tools leave different marks on the same piece of material. How can one capitalize on the positive aspects and minimize the negative ones? Realizing these relationships can only be understood as one actively engages with the process of making. 


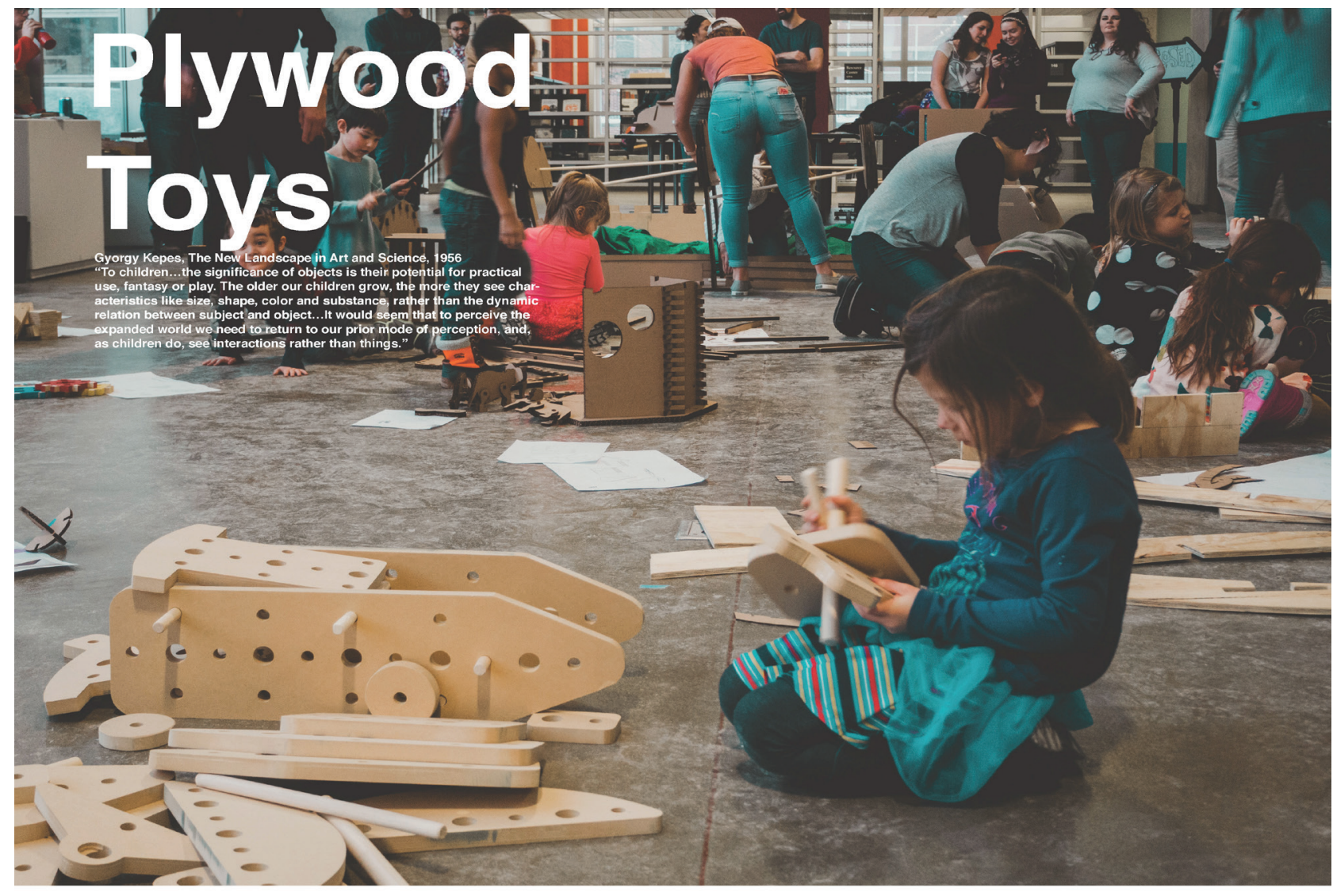

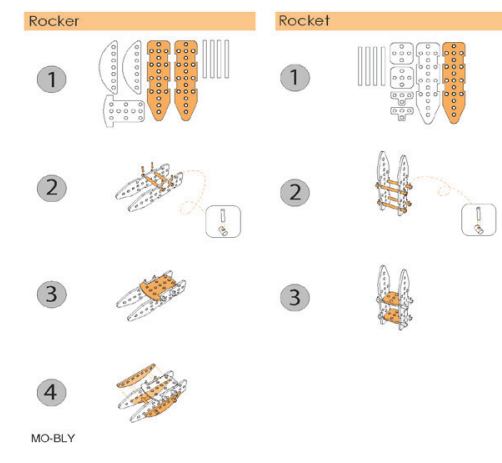

Framework
In 1967 Yale dean Charles Moore in collaboration with Kent Bloomer established one of the first permanent de-
sign/ouild studios in the country the Yale First-year Buildsign/ouild studios in the country, the Yale First-year Build-
ing Project. Yale required ALL first-year graduate students ing Project. Yale required ALL first-year graduate studen "Moore saw that getting out of the stuclio and bulling something (making) would have several benefits for the technologies, he hoped students would be inspired by the
mechanics of building." (Vlock Building Project summary)

The importance of engaging ALL students in the making process cannot be overemphasized. In its theoretical an idea is given physicality, however, these artifiacts (the drawings, models, etc.) can now be used to challenge the idea not only conceptually, but also physically. $1: 1$ exerciswe reintorce the noton that how wout them are intrinsically linked
we the
Architectural Toy ercises have been im(t) ise, at the scale of an object (and executed by an entire

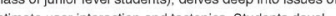

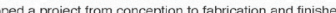
with a better understand of the relationship between ideas and making. The students were asked to design, in teams of two, a transformable toy for a child while using a limited vocabulary of shapes and a single material palette of 5 is" but the actual toy

A local museum provided funds for the Baltic ply, allowing students to experiment without the concern of cosis. In dition, the museum also displayed the best toy designs ide an exhibition called Serious Play that highlight. disseminate their ide. This provided students a venue ocal daycare served as toy testers providing dynamic

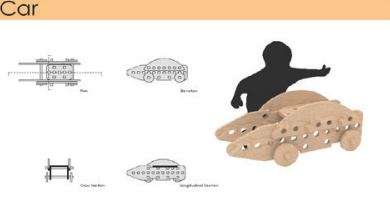

Bod

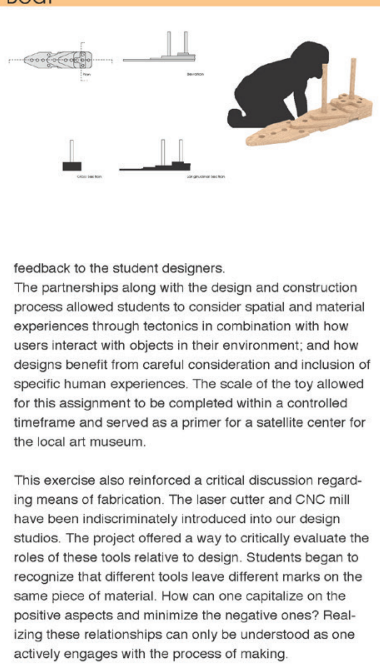

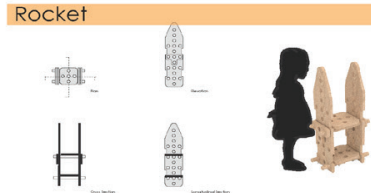

Rocker

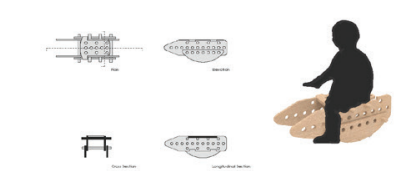

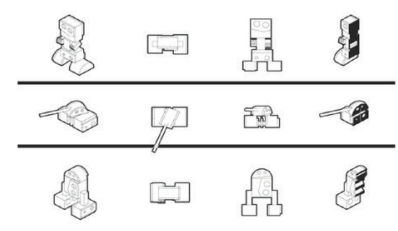

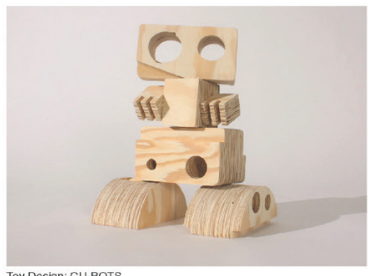

Toy Design: CU-BOTS
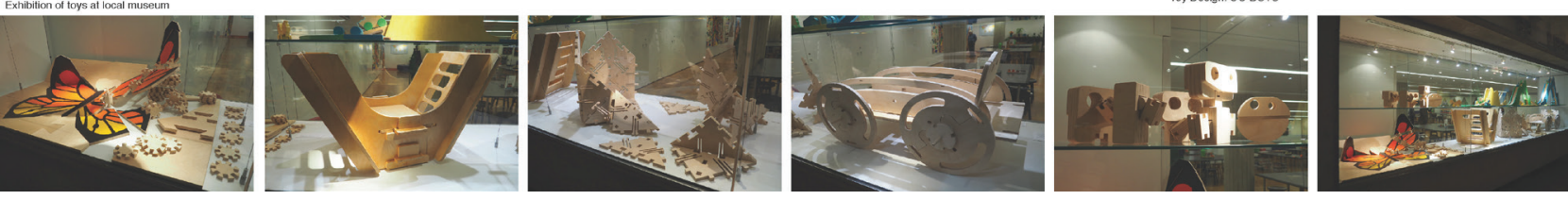